\title{
Efeito do tratamento enzimático sobre a viscosidade e os teores de fibra e pectina em suco de pitanga (Eugenia uniflora L.)
}

\author{
Effect of the enzymatic treatment on the viscosity and fiber and pectin contents of \\ pitanga (Eugenia uniflora L.) juice
}

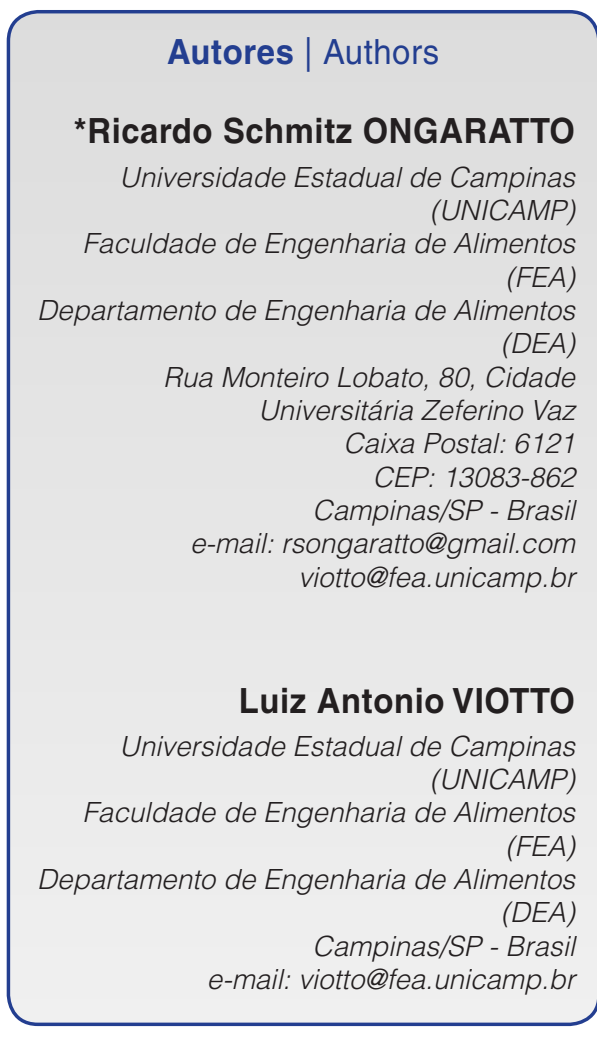

*Autor Correspondente / Corresponding Author

Recebido: Set. 10, 2014

Aprovado: Out. 29, 2015

\section{Resumo}

O objetivo deste trabalho foi avaliar o efeito do tratamento enzimático, utilizando enzimas comerciais, sobre o comportamento reológico e o teor de fibras e pectina do suco de pitanga. Foram avaliadas diferentes combinações de pectinase (Pectinex Ultra SP-L) e celulase (Cellubrix-L), totalizando 0,1\%, em massa, de enzima. Os resultados encontrados indicaram baixo valor de pectina $(<0,003 \%)$ e significativa redução no teor de fibras após tratamento enzimático, sendo que a aplicação combinada de $0,025 \%$ de pectinase com $0,075 \%$ de celulase provocou a maior redução no teor de fibras e, consequentemente, menor viscosidade do suco. Ao mesmo tempo, uma aplicação igual ou superior a 0,05\% de Pectinex Ultra SP-L foi necessária para resultar nas menores concentrações de pectina. A aplicação combinada de celulase e pectinase resultou em suco com menor viscosidade, cujo comportamento reológico foi próximo ao Newtoniano. No entanto, o modelo Lei da Potência seria o mais indicado para uso em modelagens matemáticas.

Palavras-chave: Pectinase; Celulase; Comportamento reológico; Suco de frutas.

\section{Summary}

The aim of this work was to evaluate the effect of the enzymatic treatment on the viscosity values and fiber and pectin contents of pitanga juice, applying commercial enzymes. Different combinations of pectinase (Pectinex Ultra SP-L) and cellulase (Cellubrix-L), giving a total mass of enzyme of $0.1 \%$, were evaluated. The results indicated a low value for pectin $(<0.003 \%)$ and a significant reduction in the fibre content after the enzymatic treatment. The application of $0.025 \%$ of pectinase with $0.075 \%$ of cellulase caused a greater reduction in fibre content and hence a lower viscosity of the juice. At the same time, a minimum of $0.05 \%$ of Pectinex Ultra SP-L was required to obtain the lowest pectin concentrations. The combined application of these enzymes resulted in a lower viscosity juice whose rheological behaviour was close to Newtonian, and hence the Power Law model would be more suitable for use in mathematical modelling.

Key words: Pectinase; Cellulase; Rheological behaviour; Fruit juice. 


\section{Introdução}

Muitas frutas brasileiras têm grande potencial de mercado, tornando-se interessante o estudo de processos que agreguem valor e/ou que permitam sua aplicação em novos produtos. Tradicionalmente, sucos tais como de laranja, maçã, uva e abacaxi estão bem estabelecidos. Porém, sucos com baixa escala de produção, especialmente os sucos tropicais, estão atraindo a atenção devido as suas características nutricionais e funcionais. Apesar dos estudos já existentes, ainda há uma deficiência de dados referentes ao processamento industrial de frutas tropicais, entre elas a pitanga.

A pitanga (Eugenia uniflora L.) é um fruto tropical, pertencente à família das Mirtáceas. É nativa do Brasil, especificamente das regiões Sul e Sudeste, e tem se adaptado favoravelmente às condições climáticas e edáficas do Nordeste brasileiro (BEZERRA et al., 2000). Até 2006, o estado de Pernambuco era o maior produtor em escala comercial da fruta na América Latina, com produção anual entre 1300 e 1700 toneladas (SILVA, 2006).

Dentre os frutos existentes na natureza, a pitanga está entre os que possuem maior teor de carotenoides $(225,9 \mu \mathrm{g} / \mathrm{g})$, sendo que o licopeno representa $32 \%$ desse total, e um valor significativo de vitamina $A$ (991 ER/100 g) (CAVALCANTE, 1991). Devido à sua atividade antioxidante, o licopeno é um candidato promissor como componente alimentar que pode reduzir o risco de câncer (LEE; FOO, 2013) e problemas coronários em humanos (ABETE et al., 2013; RIED; FAKLER, 2011). Ongaratto e Viotto (2009) observaram redução de 11\% no teor de carotenoides totais do suco de pitanga após tratamento enzimático com protease. Tal perda foi atribuída ao tratamento térmico decorrente da inativação enzimática. Ao mesmo tempo, a aplicação de enzimas pectinolíticas ao bagaço do pedúnculo do caju resultou em um extrato com maior teor de carotenoides, devido à ação dessas enzimas sobre as fibras do caju, facilitando a extração de tais componentes (BARBOSA et al., 2010).

Sob o ponto de vista do processamento industrial, de todas as propriedades dos fluidos é a viscosidade que requer maior atenção no estudo do escoamento destes (HAMINIUK, 2005). Quanto menor a viscosidade do fluido, menor é a perda de carga durante o escoamento, o que diminui os custos de potência com bombeamento e, consequentemente, os custos energéticos (VIDAL et al., 2006). A viscosidade é diretamente influenciada pela pectina, cuja presença pode causar ainda, em processos de filtração com membranas, incrustação e, consequentemente, a diminuição do fluxo permeado (ABDULLAH et al., 2007; ONGARATTO; VIOTTO, 2009; RAl et al., 2004). A diminuição da concentração de fibras e pectinas, seja por meio de tratamentos enzimáticos, centrifugação ou outros meios de pré-filtração, é uma das principais opções para melhorar o fluxo permeado nos processos de ultra e microfiltração (DOMINGUES et al., 2014).

A utilização de enzimas em polpas de frutas, por sua vez, diminui significativamente a viscosidade, principalmente, pela quebra das moléculas de pectina e pela redução do tamanho das fibras contidas na polpa (LEE et al., 2006; SANDRI et al., 2011; VLADISAVLJEVIC et al., 2013). Com base nisso, o objetivo deste trabalho foi avaliar o efeito do tratamento enzimático utilizando enzimas comerciais (pectinase e celulase) sobre o comportamento reológico e sobre os teores de fibra bruta e de pectina no suco comercial de pitanga.

\section{Material e métodos}

\subsection{Matéria-prima}

Para os experimentos, foi utilizada polpa de pitanga congelada da marca De Marchi (São Paulo, Brasil). A polpa foi inicialmente descongelada em banho termostático modelo NT281 (Nova Técnica, Piracicaba, $\mathrm{SP}$ ), homogeneizada e diluída na proporção de uma parte de polpa para duas partes de água, em peso, conforme sugestão do fabricante para obtenção de suco ideal para consumo, resultando em um produto com pH de 2,93 \pm 0,02 à temperatura ambiente $\left(23^{\circ} \mathrm{C}\right)$. Posteriormente, o suco foi separado em porções individuais de $200 \mathrm{~g}$ e congelado novamente, para garantir que todas as amostras que passariam por tratamento enzimático contivessem exatamente a mesma composição.

\subsection{Enzimas}

Foram utilizadas pectinase (Pectinex Ultra SP-L, com atividade padrão de 26000 PGU/mL a pH 3,5, PGU - atividade de poligalacturonase) e celulase (Cellubrix-L, com atividade padrão de 700 EGU/g, EGU - atividade de endo-glucanase). Essas enzimas são comercialmente produzidas a partir dos microrganismos Aspergillus aculeatus e Trichoderma reesei, respectivamente. Ambas enzimas foram fornecidas pela empresa Novozymes (Bagsvaerd, Dinamarca) e são utilizadas na indústria de alimentos durante o processamento de suco de frutas para reduzir sua viscosidade e/ou auxiliar na etapa de clarificação.

\subsection{Avaliação do tratamento enzimático}

Foram avaliados cinco tratamentos com concentração total de enzima de 0,1\%, em massa, e o suco sem tratamento, conforme apresentado na Tabela 1.

Para o procedimento de hidrólise, o suco foi colocado em erlenmeyers de $250 \mathrm{~mL}$ fechados e 
Tabela 1. Concentração (\%, em massa) das enzimas Pectinex Ultra SP-L e Cellubrix-L nos tratamentos avaliados.

\begin{tabular}{ccc} 
Tratamento & $\begin{array}{r}\text { Pectinex Ultra } \\
\text { SP-L (\%) }\end{array}$ & Cellubrix-L (\%) \\
\hline (a) & 0,000 & 0,000 \\
(b) & 0,100 & 0,000 \\
(c) & 0,075 & 0,025 \\
(d) & 0,050 & 0,050 \\
(e) & 0,025 & 0,075 \\
(f) & 0,000 & 0,100 \\
\hline
\end{tabular}

aquecidos em banho termostático até a temperatura de hidrólise $\left(35^{\circ} \mathrm{C}\right)$. Em seguida, as enzimas foram adicionadas ao suco, e este mantido em agitador modelo TE-421 (Tecnal, Piracicaba, SP) sob temperatura de $35{ }^{\circ} \mathrm{C}$ e agitação de $150 \mathrm{rpm}$, durante 105 minutos. Ao final de cada ensaio, o suco tratado foi aquecido em banho termostático até as condições de inativação enzimática ( $80^{\circ} \mathrm{C} / 5 \mathrm{~min}$, para ambas as enzimas) e resfriado até $30^{\circ} \mathrm{C}$. Foram realizadas análises de pectina, segundo método de Carré e Haynes (PEARSON, 1970) e fibra (AACC, 1976), todas em triplicata. Para melhor entendimento dos efeitos do tratamento enzimático, foram realizados estudos do comportamento reológico e de microscopia óptica.

\subsubsection{Comportamento reológico}

O comportamento reológico das amostras foi estudado utilizando-se viscosímetro (Brookfield, Middleboro, EUA), modelo LVDV II+ e Splindle S-18. As amostras foram homogeneizadas em agitador magnético a $150 \mathrm{rpm}$ durante 1 minuto. A temperatura de análise foi de $30{ }^{\circ} \mathrm{C}$, e esta era controlada por meio de um banho termostático modelo MLW UH4 (VEB Prüfgeräte-Werk, Medingen, Alemanha). Foram obtidos valores de viscosidade aparente para velocidades rotacionais de 40 a 140 rpm. Para realização do ajuste dos dados aos diferentes modelos, essas velocidades foram convertidas em taxa de deformação $(\gamma)\left(s^{-1}\right)$, enquanto que a viscosidade aparente $\left(\mu_{\mathrm{a}}\right)(\mathrm{Pa} \cdot \mathrm{s})$ foi convertida em tensão de cisalhamento $(\tau)(\mathrm{Pa})$ a partir da Equação 1:

$\mu_{\mathrm{a}}=\frac{\tau}{\gamma}$

Os valores experimentais da tensão de cisalhamento e da taxa de deformação foram ajustados aos modelos da Lei da Potência (Equação 2), Herschel-Bulkley (Equação 3) e Mizrahi-Berk (Equação 4), através de regressão não-linear, utilizando-se o software Statistica 7.0 (StatSoft, Tulsa, EUA), tendo sido determinados os parâmetros reológicos desses modelos, assim como os respectivos coeficientes de determinação $\left(R^{2}\right)$ e o qui-quadrado $\left(\chi^{2}\right)$. Todas as análises foram realizadas em triplicata.

$$
\begin{aligned}
& \tau=\mathrm{K} \gamma^{\mathrm{n}} \\
& \tau=\tau_{0}+\mathrm{K} \gamma^{\mathrm{n}} \\
& \tau^{0,5}=\mathrm{K}_{0 \mathrm{M}}+\mathrm{K} \gamma^{\mathrm{n}}
\end{aligned}
$$

\subsubsection{Microscopia óptica}

Visto que não existe uma metodologia específica de elaboração das amostras para microscopia óptica, o procedimento ora adotado foi determinado por meio de tentativa e erro, ou seja, tentativas aleatórias até obter resultados visuais satisfatórios. Todas as amostras foram homogeneizadas com a ajuda de agitador magnético a 500 rpm durante 5 minutos. De cada uma das amostras homogeneizadas retirou-se $50 \mu \mathrm{L}$ de solução, que foram espalhados suave e uniformemente sobre a placa de observação. As amostras foram fixadas nas placas por ação de calor, com o auxílio de secador de ar quente. Uma vez fixadas e secas, as amostras foram descoloridas com álcool etílico e coloridas com azul de metileno (1\% em álcool) para dar contraste. Logo após, o excesso de corante foi removido mergulhando a placa em álcool etílico, seguido de secagem com secador de ar quente. Foi utilizado o microscópio óptico, modelo 250-CF (Jena Microscopes, Jena, Alemanha), com lentes Carl Zeiss Jena, adaptador de câmera e sistema microfotográfico mf-AKS com conexão para TV, lâmpada de luz halogenada de 6 V, 25 W, tipo HLW-S-5-A. As amostras foram observadas com aumento de 30 vezes.

\section{Resultados e discussão}

\subsection{Tratamento enzimático}

A microestrutura do suco de pitanga é composta por uma matriz de formato irregular, tendo como principais constituintes as pectinas e fibras (Figura 1a). Sabe-se que as pectinas, mesmo em baixas concentrações, em soluções aquosas e em presença de açúcares e ácidos (como ácido cítrico e málico) formam géis muito estáveis (BOBBIO; BOBBIO, 2001). Essa consistência gel pode ser melhor observada nos detalhes apresentados na Figura 1 (exceto Figura 1b), onde é possível visualizar um aglomerado formado por uma estrutura fibrosa (regiões mais escuras) coberta por uma camada geleificada (regiões mais claras). Essa configuração estrutural foi, também, descrita por Aguilera e Stanley (1999), os quais afirmaram que em tecidos vegetais as microfibrilas de celulose são englobadas por uma matriz amorfa composta principalmente por substâncias pécticas.

O suco que passou pelo tratamento enzimático apenas com Pectinex Ultra SP-L resultou em regiões nas quais a camada geleificada constituída por substâncias 
Efeito do tratamento enzimático sobre a viscosidade e os teores de fibra e pectina em suco de pitanga (Eugenia uniflora L.) ONGARATTO, R. S.; VIOTTO, L. A

pécticas se apresentou menos densa ficando evidente a presença de estruturas fibrosas (Figura 1b). Apesar de apenas as estruturas fibrosas estarem identificadas na Figura 1b e a análise quantitativa ter identificado um teor muito pequeno de pectina (Tabela 2), ainda é possível observar a presença de uma camada geleificada ao redor das fibras. Mesmo após o tratamento enzimático com pectinases, é comum a presença de pectina no suco (ALVAREZ et al., 1998; MUTLU et al., 1999; PINELO et al., 2010).
Para os experimentos nos quais Pectinex Ultra SP-L e Cellubrix-L foram aplicadas simultaneamente (Figura 1c-e), não foram observadas mudanças visuais entre os diferentes tratamentos a partir da microscopia. Notou-se, apenas, a ação da pectinase devido à presença de regiões mais claras e a ação da celulase decorrente da diminuição das partículas fibrosas.

Pectinex Ultra SP-L apresenta diferentes atividades enzimáticas, tais como poligalacturonase, pectinesterase e celulase (ABDULLAH et al., 2007; RODRIGUES et al.,
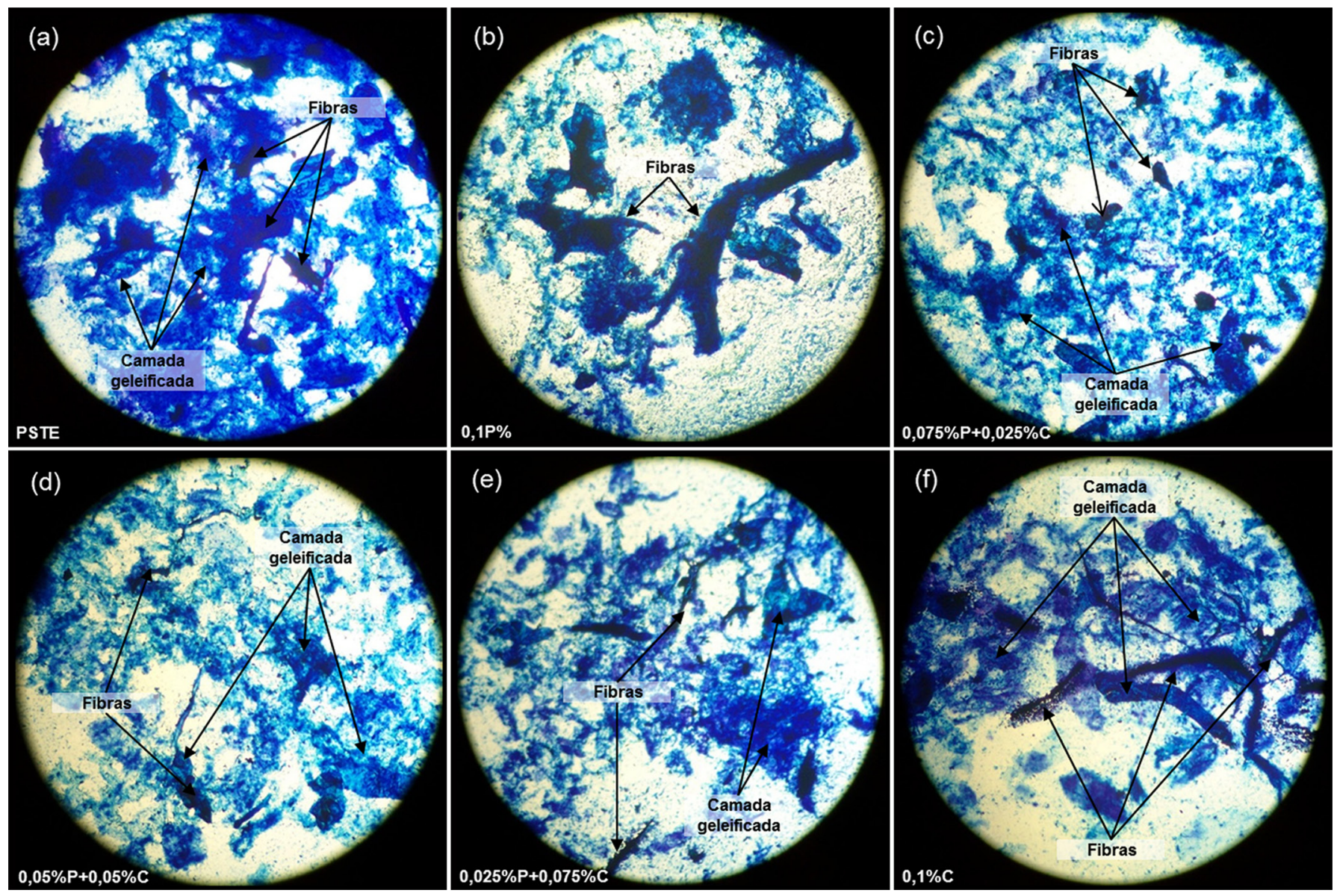

Figura 1. Fotomicrografias do suco de pitanga sem tratamento enzimático (a) e tratado com $0,1 \%$ de Pectinex Ultra SP-L (b); 0,075\% de Pectinex Ultra SP-L e 0,025\% de Cellubrix-L (c); 0,05\% de Pectinex Ultra SP-L e 0,05\% de Cellubrix-L (d); 0,025\% de Pectinex Ultra SP-L e 0,075\% de Cellubrix-L (e); e 0,1\% de Cellubrix-L (f).

Tabela 2. Concentração de fibra e pectina no suco de pitanga com e sem tratamento enzimático.

\begin{tabular}{|c|c|c|c|c|}
\hline Tratamento & [Enzima] & $\begin{array}{c}\text { Fibra } \\
(\%)\end{array}$ & $\begin{array}{c}\text { Pectina } \\
(\%)\end{array}$ & $\begin{array}{c}\text { Viscosidade } \\
\text { (mPa.s)* }^{\star}\end{array}$ \\
\hline (a) & PSTE & $4,09 \times 10^{-2(a)}$ & $1,48 \times 10^{-2(a)}$ & $2,85^{(a)}$ \\
\hline (b) & $0,1 \% \mathrm{P}$ & $3,32 \times 10^{-2(a b)}$ & $4,70 \times 10^{-4(b)}$ & $2,32^{(b)}$ \\
\hline (c) & $0,075 \% P+0,025 \% C$ & $2,85 \times 10^{-2(b c)}$ & $1,12 \times 10^{-3(b)}$ & $1,93^{(c d)}$ \\
\hline (d) & $0,05 \% P+0,05 \% C$ & $2,30 \times 10^{-2(c)}$ & $1,47 \times 10^{-3(b c)}$ & $1,86^{(c)}$ \\
\hline (e) & $0,025 \% P+0,075 \% C$ & $1,21 \times 10^{-2(d)}$ & $3,34 \times 10^{-3(c)}$ & $1,78^{(\mathrm{e})}$ \\
\hline (f) & $0,1 \% \mathrm{C}$ & $2,20 \times 10^{-2(c)}$ & $1,27 \times 10^{-2(d)}$ & $2,00^{(d)}$ \\
\hline
\end{tabular}

*viscosidade para taxa de deformação de $52 \mathrm{~s}^{-1}$. Letras diferentes (na mesma coluna) significam diferença estatística, considerando nível de confiabilidade de 90\%. C = Cellubrix-L. P = Pectinex Ultra SP-L. PSTE = Suco sem Tratamento Enzimático. 
2009). A presença de celulase na Pectinex Ultra SP-L pode ser observada nos resultados reportados por Matta et al. (2004). Esses autores observaram uma redução de $61 \%$ no teor de fibras em suco de acerola após tratamento enzimático utilizando essa enzima. No entanto, os resultados ora encontrados permitem observar um efeito sinérgico entre a ação de celulases e pectinases. Mesmo que a composição de Pectinex Ultra SP-L apresente celulases e pectinases, fica evidente 0 efeito principal das pectinases. Rodrigues et al. (2009) reportaram atividade de celulase de $19,5 \mathrm{U} / \mathrm{g}$, enquanto que a atividade de poligalacturonase foi de 500,9 U/g para Pectinex Ultra SP-L.

O principal efeito da pectinase é hidrolisar os polissacarídeos pécticos e expor a celulose e hemicelulose à degradação enzimática. A partir da combinação com uma celulase, o efeito sobre a quebra das fibras é melhorado, ou seja, a ação da pectinase facilita a ação da celulase, uma vez que a primeira rompe a barreira formada pela pectina ao redor das fibras, permitindo a atuação das celulases sobre as partículas fibrosas (SHALOM, 1986). Esse fato pode ser observado na Figura 1f, na qual fica evidente que a celulase conseguiu agir apenas em regiões expostas, enquanto que a matriz péctica presente nos arredores das fibras impediu a ação dessa enzima. Além disso, os resultados presentes na Tabela 2 corroboram esse comportamento, uma vez que a concentração de fibra foi maior para o tratamento com a maior concentração de celulase quando comparado com o tratamento (e), o qual continha pectinase. Ao mesmo tempo, a aplicação isolada de Pectinex Ultra SP-L não atuou de forma significativa sobre a quebra das partículas de fibra, conforme verificado pelos resultados reportados na Tabela 2.

Analiticamente, foi observado que a quantidade de fibra e pectina diminuiu à medida que se aumentou a concentração de celulase e pectinase, respectivamente (Tabela 2). O erro experimental foi inferior a 10\%, tanto para as análises de fibra quanto às de pectina.

A redução da viscosidade está diretamente associada com a redução dos sólidos suspensos, nos quais as fibras representam uma parcela importante (VIDAL et al., 2006). Sendo assim, para uma eficiente redução da viscosidade se faz necessária a aplicação de enzimas que consigam atuar sobre as partículas fibrosas do suco, tal como as celulases. A ação de pectinases, por sua vez, está relacionada, principalmente, à redução da turbidez provocada pela presença da pectina (PINELO et al., 2010; SANDRI et al., 2011; MAKTOUF et al., 2014). Como uma consequência da aplicação de pectinases há a redução da viscosidade do substrato (ABDULLAH et al., 2007; MAKTOUF et al., 2014).
A partir dos resultados encontrados, notou-se o efeito sinérgico existente na atuação da pectinase e celulase. Esse efeito também foi observado por Çinar (2005) durante a extração de carotenoides de plantas e por Wilkins et al. (2007). Dessa forma, quando o objetivo principal estiver relacionado à diminuição da viscosidade, seja para facilitar as condições de escoamento ou para outra finalidade distinta, a aplicação isolada de pectinase não apresentará um efeito significativo quando comparado com a ação conjunta de pectinases e celulases. Ao mesmo tempo, a aplicação isolada de celulases não fornecerá o efeito desejado devido à presença de pectina no substrato (suco de fruta), que forma uma barreira ao redor das fibras, dificultando a ação das celulases.

\subsection{Comportamento reológico}

As maiores reduções de viscosidade ocorreram para a aplicação de 0,025\% de Pectinex Ultra SP-L e 0,075\% de Cellubrix-L (Figura 2). Esse comportamento está de acordo com os resultados apresentados na Tabela 2, na qual é possível verificar que a aplicação de pectinase, independente da concentração, resultou em valores praticamente nulos de pectina, assim como a presença de celulase ocasionou a redução das fibras totais presentes. Foi observado erro experimental inferior a 3\% nas análises de viscosidade.

A aplicação de celulase resultou em comportamento reológico mais próximo ao Newtoniano, com $\mathrm{R}^{2}$ superior a 0,95 . Para o suco sem tratamento e para o tratado apenas com pectinase, o modelo Newtoniano apresentou $\mathrm{R}^{2}$ de 0,85 e 0,90, respectivamente (Tabela 3 ). O modelo de Mizrahi-Berk foi o que apresentou o melhor ajuste para os dados experimentais, uma vez que resultou nos maiores coeficientes de correlação $\left(R^{2}\right)$ e $\chi^{2}$ iguais a zero para todos

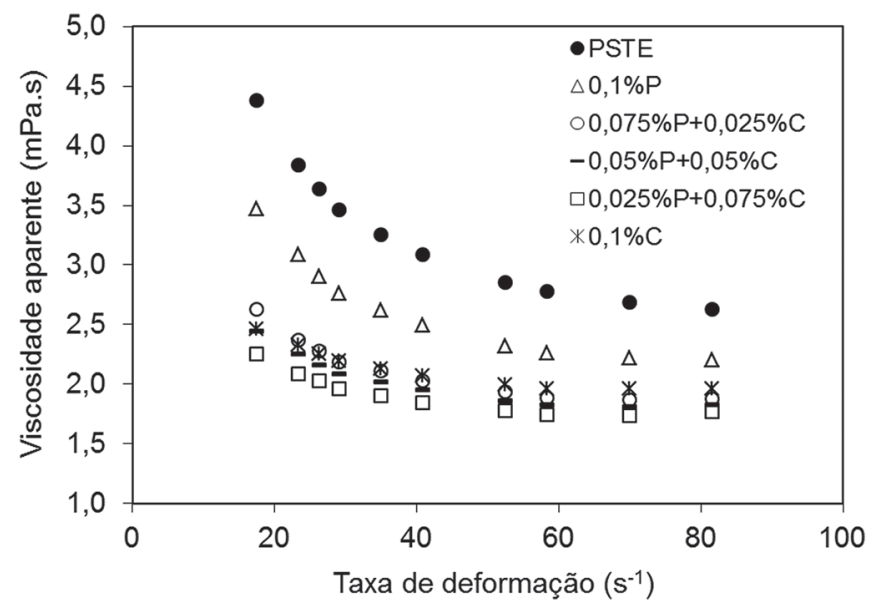

Figura 2. Relação entre viscosidade aparente e taxa de deformação para o suco de pitanga com e sem tratamento enzimático (PSTE = Suco Sem Tratamento Enzimático; $C=$ Cellubrix-L; $P$ = Pectinex Ultra SP-L). 
Efeito do tratamento enzimático sobre a viscosidade e os teores de fibra e pectina em suco de pitanga (Eugenia uniflora L.) ONGARATTO, R. S.; VIOTTO, L. A.

Tabela 3. Parâmetros reológicos e estatísticos para o suco de pitanga antes e após tratamento enzimático.

\begin{tabular}{|c|c|c|c|c|c|c|}
\hline & Tratamento & --- & $\mathbf{K}$ & -- & $\mathbf{R}^{2}$ & $\chi^{2}$ \\
\hline \multirow{6}{*}{ Newtoniano } & (a) & --- & 0,0096 & --- & 0,8533 & 0,0023 \\
\hline & (b) & --- & 0,0067 & --- & 0,8981 & 0,0012 \\
\hline & (c) & --- & 0,0041 & --- & 0,9572 & 0,0004 \\
\hline & (d) & --- & 0,0036 & --- & 0,9673 & 0,0003 \\
\hline & (e) & --- & 0,0030 & --- & 0,9792 & 0,0002 \\
\hline & $(f)$ & --- & 0,0034 & --- & 0,9810 & 0,0002 \\
\hline & Tratamento & -- & $\mathbf{K}$ & $\mathbf{n}$ & $\mathbf{R}^{2}$ & $\chi^{2}$ \\
\hline \multirow{6}{*}{$\begin{array}{c}\text { Lei da } \\
\text { potência }\end{array}$} & (a) & --- & 0,0096 & 0,7007 & 0,9944 & 0,0001 \\
\hline & (b) & --- & 0,0067 & 0,7412 & 0,9921 & 0,0001 \\
\hline & (c) & --- & 0,0041 & 0,8191 & 0,9943 & 0,0000 \\
\hline & (d) & --- & 0,0036 & 0,8392 & 0,9958 & 0,0000 \\
\hline & (e) & --- & 0,0030 & 0,8726 & 0,9951 & 0,0000 \\
\hline & $(f)$ & --- & 0,0034 & 0,8714 & 0,9979 & 0,0001 \\
\hline & Tratamento & $\tau_{0}$ & $\mathbf{K}$ & $n$ & $\mathbf{R}^{2}$ & $\chi^{2}$ \\
\hline \multirow{7}{*}{$\begin{array}{l}\text { Hershel- } \\
\text { Bulkley }\end{array}$} & (a) & 0,0273 & 0,0038 & 0,8807 & 0,9984 & 0,0000 \\
\hline & (b) & 0,0180 & 0,0032 & 0,8851 & 0,9960 & 0,0001 \\
\hline & (c) & 0,0119 & 0,0022 & 0,9420 & 0,9977 & 0,0001 \\
\hline & (d) & 0,0110 & 0,0020 & 0,9586 & 0,9977 & 0,0001 \\
\hline & (e) & 0,0064 & 0,0021 & 0,9391 & 0,9967 & 0,0001 \\
\hline & $(f)$ & 0,0026 & 0,0030 & 0,8905 & 0,9979 & 0,0000 \\
\hline & Tratamento & $\mathbf{K}_{0 M}$ & K & $\mathbf{n}$ & $\mathbf{R}^{2}$ & $\chi^{2}$ \\
\hline \multirow{6}{*}{ Mizrahi-Berk } & (a) & 0,1797 & 0,0065 & 0,8220 & 0,9996 & 0,0000 \\
\hline & (b) & 0,1389 & 0,0085 & 0,7697 & 0,9997 & 0,0000 \\
\hline & (c) & 0,1266 & 0,0097 & 0,7417 & 0,9996 & 0,0000 \\
\hline & (d) & 0,1211 & 0,0091 & 0,7600 & 0,9995 & 0,0000 \\
\hline & (e) & 0,1031 & 0,0160 & 0,6626 & 0,9999 & 0,0000 \\
\hline & $(f)$ & 0,1886 & 0,0110 & 0,7283 & 0,9999 & 0,0000 \\
\hline
\end{tabular}

os experimentos. Os demais modelos (Lei da Potência e Herschel-Bulkley) também apresentaram ótimos ajustes com $\mathrm{R}^{2}$ superiores a 0,99 e $\chi^{2}$ muito próximos de zero. Comportamento semelhante já foi observado para suco de acerola (SILVA et al., 2005) e jabuticaba (SATO; CUNHA, 2007), uma vez que tanto o modelo Lei da Potência quanto o modelo de Herschel-Bulkley foram os mais adequados, destacando-se o segundo. O modelo Lei da Potência, por sua vez, foi o que melhor descreveu o comportamento reológico do suco de mirtilo (CEPEDA et al., 2002) e da polpa de manga centrifugada (VIDAL et al., 2006).

O ajuste a diferentes modelos reológicos mostrou que os sucos de pitanga sem tratamento, assim como o tratado apenas com pectinase, apresentaram comportamento pseudoplástico mais acentuado, visto que o índice de comportamento " $n$ " para esses dois casos foram menores $(0,70$ e 0,74, respectivamente), enquanto que para os demais ensaios obteve-se índice de comportamento do fluido superior a 0,8 , aproximando-se ao comportamento de fluido Newtoniano.

\section{Conclusão}

A aplicação combinada de 0,025\% de Pectinex Ultra SP-L e 0,075\% de Cellubrix-L apresentou os melhores resultados tanto para redução da quantidade de fibras quanto para viscosidade. Porém, as menores concentrações de pectina foram obtidas com aplicação superior a 0,05\% de Pectinex Ultra SP-L. Além disso, os sucos sem tratamento, assim como o tratado apenas com pectinase, apresentaram comportamento tipicamente pseudoplástico, enquanto que para os demais casos, o suco final apresentou comportamento próximo ao Newtoniano. No entanto, o modelo Lei da Potência seria o mais indicado para aplicação em modelagens matemáticas, por ter apresentado ótimo ajuste dos dados experimentais e por apresentar apenas um parâmetro.

\section{Agradecimentos}

À coordenação de Aperfeiçoamento de Pessoal de Nível Superior (CAPES) pelo apoio financeiro que possibilitou a realização deste trabalho. 
Efeito do tratamento enzimático sobre a viscosidade e os teores de fibra e pectina em suco de pitanga (Eugenia uniflora L.) ONGARATTO, R. S.; VIOTTO, L. A.

\section{Referências}

ABDULLAH, A. G. L.; SULAIMAN, N. M.; AROUA, M. K.; NOOR, M. J. M. M. Response surface optimization of conditions for clarification of carambola fruit juice using a commercial enzyme. Journal of Food Engineering, Essex, v. 81, n. 1, p. 65-71, 2007. http://dx.doi.org/10.1016/j.jfoodeng.2006.10.013.

ABETE, I.; PEREZ-CORNAGO, A.; NAVAS-CARRETERO, S.; BONDIA-PONS, I.; ZULET, M. A.; MARTINEZ, J. A. A regular lycopene enriched tomato sauce consumption influences antioxidant status of healthy young-subjects: a crossover study. Journal of Functional Foods, v. 5, n. 1, p. 28-35, 2013. http:// dx.doi.org/10.1016/j.jff.2012.07.007

AGUILERA, J. M.; STANLEY, D. W. Microstructural principles of food processing and engineering. 2nd ed. Gaithersburg: Aspen Publication, 1999. 432 p.

ALVAREZ, S.; ALVAREZ, R.; RIERA, F. A.; COCA, J. Influence of depectinization on apple juice ultrafiltration. Colloids and Surfaces A, Physicochemical and Engineering Aspects, Amsterdam, v. 139, n. 2-3, p. 377-382, 1998. http://dx.doi. org/10.1016/S0927-7757(98)00235-0.

AMERICAN ASSOCIATION OF CEREAL CHEMISTS - AACC. Approved methods of the American Association of Cereal Chemists. 7th ed. St. Paul: AACC, 1976. 256 p.

BARBOSA, M. M.; PINTO, G. A. S.; BRITO, E. S.; RODRIGUES, R. D. Avaliação da eficiência de maceração enzimática no bagaço do pedúnculo do caju para a obtenção de carotenoides. In: CONGRESSO BRASILEIRO DE ENGENHARIA QUÍMICA, 18., 2010, Foz do Iguaçu. Anais... São Paulo: Associação Brasileira de Engenharia Química, 2010. p. 830-838.

BeZERRA, J. E. F.; SILVA, J. F.; LedermAN, I. E. Pitanga (Eugenia uniflora L.). Jaboticabal: Funep, 2000. 30 p. (Série Frutas Nativas, 1).

BOBBIO, P. A.; BOBBIO, F. O. Química do processamento de alimentos. 3. ed. Campinas: Editora Varela, 2001. 143 p.

CAVALCANTE, M. L. Composição de carotenóides e valor de vitamina A em pitanga (Eugenia uniflora L.) e acerola (Malpighia glabra L.). 1991. 86 f. Dissertação (Mestrado em Nutrição)-Universidade Federal do Rio de Janeiro, Rio de Janeiro, 1991.

CEPEDA, E.; HERMOSA, M.; LLORENS, F.; VILLARÁN, M. C. Rheological behaviour of blueberry cloudy juice (Vacciniumm corymdosum L.). International Journal of Food Science \& Technology, Oxford, v. 37, n. 3, p. 371-376, 2002. http://dx.doi. org/10.1046/j.1365-2621.2002.00566.x.

ÇINAR, I. Effects of cellulose and pectinase concentrations on the colour yield of enzyme extracted plant carotenoids. Process Biochemistry, London, v. 40, n. 2, p. 945-949, 2005. http:// dx.doi.org/10.1016/j.procbio.2004.02.022.
DOMINGUES, R. C. C.; RAMOS, A. A.; CARDOSO, V. L.; REIS, M. H. M. Microfiltration of passion fruit juice using hollow fibre membranes and evaluation of fouling mechanisms. Journal of Food Engineering, Essex, v. 121, n. 1, p. 73-79, 2014. http:// dx.doi.org/10.1016/j.jfoodeng.2013.07.037.

HAMINIUK, C. W. I. Comportamento reológico e fracionamento péctico das polpas integrais de araçá (Psidium catlleianum sabine) e amora-preta (Rubus spp). 2005. 85 f. Dissertação (Mestrado em Tecnologia de Alimentos)-Universidade Federal do Paraná, Curitiba, 2005

LEE, L. K.; FOO, K. Y. An appraisal of the therapeutic value of lycopene for the chemoprevention of prostate cancer: a nutrigenomic approach. Food Research International, Oxford, v. 54, n. 1, p. 1217-1228, 2013. http://dx.doi.org/10.1016/j. foodres.2013.03.027

LEE, W. C.; YUSOF, S.; HAMID, N. S. A.; BAHARIN, B. S. Optimizing conditions for enzymatic clarification of banana juice using response surface methodology (RSM). Journal of Food Engineering, Essex, v. 73, n. 1, p. 55-63, 2006. http://dx.doi. org/10.1016/j.jfoodeng.2005.01.005

MAKTOUF, S.; NEIFAR, M.; DRIRA, S. J.; BAKLOUTI, S.; FENDRI, M.; CHÂABOUNI, S. E. Lemon juice clarification using fungal pectinolytic enzymes coupled to membrane ultrafiltration. Food and Bioproducts Processing, Rugby, v. 92, n. 1, p. 14-19, 2014. http://dx.doi.org/10.1016/j.fbp.2013.07.003.

MATTA, V. M.; MORETTI, R. H.; CABRAL, L. M. C. Microfiltration and reverse osmosis for clarification and concentration of acerola juice. Journal of Food Engineering, Essex, v. 61, n. 3, p. 477-482, 2004. http://dx.doi.org/10.1016/S02608774(03)00154-7.

MUTLU, M.; SARIOGLU, K.; DEMIR, N.; ERCAN, M. T.; ACAR, $J$. The use of comercial pectinase in fruit juice industry. Part I: viscosimetric determination of enzyme activity. Journal of Food Engineering, Essex, v. 41, n. 3-4, p. 147-150, 1999. http://dx.doi. org/10.1016/S0260-8774(99)00088-6.

ONGARATTO, R. S.; VIOTTO, L. A. Clarificação do suco de pitanga (Eugenia uniflora L.) e concentração de carotenoides por microfiltração e ultrafiltração. Brazilian Journal of Food Technology, Campinas, VII BMCFB, p. 85-93, 2009.

PEARSON, D. The chemical analysis of foods. 6th ed. London: J. \& A. Churchill, 1970. 604 p.

PINELO, M.; ZEUNER, B.; MEYER, A. S. Juice clarification by protease and pectinase treatments indicates new roles of pectin and protein in cherry juice turbidity. Food and Bioproducts Processing, Rugby, v. 88, n. 2-3, p. 259-265, 2010. http://dx.doi. org/10.1016/j.fbp.2009.03.005.

RAI, P.; MAJUMDAR, G. C.; DASGUPTA, S.; DE, S. Optimizing pectinase usage in pretreatment of mosambi juice for clarification by response surface methodology. Journal of Food 
Engineering, Essex, v. 64, n. 3, p. 397-403, 2004. http://dx.doi. org/10.1016/j.jfoodeng.2003.11.008.

RIED, K.; FAKLER, P. Protective effect of lycopene on serum cholesterol and blood pressure: Meta-analyses of intervention trials. Maturitas, Amsterdam, v. 68, n. 4, p. 299-310, 2011. http:// dx.doi.org/10.1016/j.maturitas.2010.11.018. PMid:21163596.

RODRIGUES, R. D. P.; BARBOSA, M. M.; PINTO, G. A. S.; BRITO, E. S. Avaliação do efeito da adição de enzimas comerciais sobre o extrato de bagaço de caju. In: SIMPÓSIO NACIONAL DE BIOPROCESSOS, 17., 2009, Natal. Anais... Natal: Universidade Federal do Rio Grande do Norte, 2009.

SANDRI, I. G.; FONTANA, R. C.; BARFKNECHT, D. M.; SILVEIRA, M. M. Clarification of fruit juices by fungal pectinases. Food Science and Technology, Campinas, v. 44, n. 10, p. 2217-2222, 2011. http://dx.doi.org/10.1016/j.Iwt.2011.02.008.

SATO, A. C. K.; CUNHA, R. L. Influência da temperatura no comportamento reológico da polpa de jabuticaba. Food Science and Technology, Campinas, v. 27, n. 4, p. 890-896, 2007. http://dx.doi.org/10.1590/S0101-20612007000400033.

SHALOM, N. B. Hindrance of hemicelluloses and cellulose hydrolysis by pectic substances. Journal of Food Science, Champaign, v. 51, n. 3, p. 720-721, 1986. http://dx.doi. org/10.1111/j.1365-2621.1986.tb13919.x.
Silva, F. C.; Guimarães, D. H. P.; GASPARETto, C. A. Reologia do suco de acerola: efeitos da concentração e temperatura. Food Science and Technology, Campinas, v. 25, n. 1, p. 121-126, 2005. http://dx.doi.org/10.1590/S010120612005000100020.

SILVA, S. M. Pitanga. Revista Brasileira de Fruticultura, Jaboticabal, v. 28, n. 1, 2006. http://dx.doi.org/10.1590/S010029452006000100001.

VIDAL, J. R. M. B.; SIERAKOWISKI, M. R.; HAMINIUK, C. W. I.; MASSON, M. L. Propriedades reológicas da polpa de manga (Mangifera indica L. cV Keitt) centrifugada. Ciência e Agrotecnologia, Lavras, v. 30, n. 5, p. 955-960, 2006. http:// dx.doi.org/10.1590/S1413-70542006000500020.

VLADISAVLJEVIC, G. T.; VUKOSAVLJEVIC, P.; VELJOVIC, M. $S$. Clarification of red raspberry juice using microfiltration with gas backwashing: A viable strategy to maximize permeate flux and minimize a loss of anthocyanins. Food and Bioproducts Processing, Rugby, v. 91, n. 4, p. 473-480, 2013. http://dx.doi. org/10.1016/j.fbp.2013.05.004.

WILKINS, M.; WIDMER, W. W.; GROHMANN, K.; CAMERON, R. G. Hydrolysis of grapefruit peel waste with cellulose and pectinase enzymes. Bioresource Technology, Essex, v. 98, n. 8, p. 1596-1601, 2007. http://dx.doi.org/10.1016/j. biortech.2006.06.022. PMid:16934453. 